\title{
PENGARUH STANDAR LANTANUM TERHADAP VALIDASI METODE PENGUKURAN NEODIMIUM DAN SERIUM MENGGUNAKAN X-RAY FLUORESCENCE (XRF)
}

\section{The Effect Of Lantanum Standards On The Validation Of Neodimium And Serium Measurement Methods Using XRF Spectrometer}

\author{
Rosika Kriswarini ${ }^{1}$, Erlina Noerpitasari ${ }^{2}$, Noviarty ${ }^{3}$, Sutri Indaryati ${ }^{4}$, dan Arif Nugroho ${ }^{5}$ \\ 1,2,3,4,5 Pusat Teknologi Bahan Bakar Nuklir (PTBBN)-BATAN \\ Gedung 20, Kawasan PUSPIPTEK, Tangerang Selatan
}

E-mail: rosika@batan.go.id

\begin{abstract}
Abstrak
Telah dilakukan analisis unsur Neodimium (Nd) dan Serium (Ce) pada sampel cair menggunakan XRF. Spektrometer. XRF pada umumnya digunakan untuk analisis sampel berbentuk padat. Bila sampel yang dianalisis berbentuk cair maka perlu preparasi khusus agar hasil analisis memenuhi persyaratan pengujian dan memenuhi kriteria keselamatan. Laarutan standar $\mathrm{Nd}$ dan Ce sebanyak 50uL diteteskan di kertas saring berdiameter $24 \mathrm{~mm}$ dengan konsentrasi yang bervariasi 200, 400, 600, 800 dan 1000ppm tanpa pembanding La dan dengan pembanding La dan yang selanjutnya dianalisis menggunakan XRF. Kurva kalibrasi dari hasil pengukuran berupa korelasi antara konsentrasi dan intensitas. Berdasarkan dua jenis kurva kalibrasi tersebut diperoleh linearitas kurva dengan nilai koefisien korelasi ( $r$ ) Nd sebesar 0,9738 tanpa standar La, dan 0,9990 menggunakan standar La. Sedangan Ce diperoleh nilai $r$ sebesar 0,9772 tanpa standar La, dan 0,9992 dengan La. Limit deteksi (LoD) dan limit kuantitasi (LoQ) dihitung dengan melakukan pengukuran intensitas setiap unsur dalam larutan blanko sedangkan presisi dan akurasi pengukuran dengan rentang konsentrasi antara 0 sampai dengan 1000 ppm. Hasil analisis menggunakan standar La memenuhi kriteria keberterimaan dalam pengujian yaitu lebih dari $95 \%$. Berdasarkan hal tersebut maka dapat dinyatakan bahwa analisis unsur dalam larutan $\mathrm{Nd}$ dan $\mathrm{Ce}$ dengan teknik tetes menggunakan standar La lebih akurat dibanding tanpa menggunakan standar La. Metode tetes untuk pengukuran $\mathrm{Nd}$ dan $\mathrm{Ce}$ menggunakan standar La telah tervalidasi dengan LoD, LoQ presisi dan akurasi, masingmasing -8,94 ppm, 0,76 ppm, 1,06\%, dan 95,43\%, untuk unsur Nd. Sedangkan untuk unsur Ce nilainya 31,69 ppm, 108,78 ppm, $1,43 \%$ dan $95,77 \%$,
\end{abstract}

Kata kunci: validasi metode, standar La, XRF, larutan neodymium dan serium

\begin{abstract}
Neodymium ( $\mathrm{Nd}$ ) and Cerium (Ce) elemental analysis has been carried out in solution sample using XRF which was generally used for the analysis of solid samples. Special preparation was needed for sample solution so that the analysis results met the testing requirements and safety criteria. The Nd and Ce solution as much as 50uL was dropped on $24 \mathrm{~mm}$ diameter of filter paper with various concentrations of 200, 400,600, 800 and 1000ppm without La and with La standard. Next, the sample was analyzed using XRF. The calibration curve from the measurement results showed correlation between concentration and intensity. Based on the two kinds of calibration curves, a linearity curve was obtained with the correlation coefficient (r) Nd of 0.9738 without La, and 0.9990 using La, while the $r$ of Ce was 0.9772 without La, and 0.9992 using La. The detection limit (LoD) and quantification limit (LoQ) was calculated by measuring the intensity of each element in a blank solution, while the precision and accuracy of the measurements was in the concentration range between 0 and $1000 \mathrm{ppm}$. The analysis using the La met the acceptance criteria, which was more than $95 \%$. It could be stated that the Nd and Ce elemental analysis in solutions using the drop technique using La was more accurate than without La. The drop method for measurement of Nd and Ce using $L a$ was valid.with $L O D$, LoQ, precision and accuracy -8.94 ppm, 0.76 ppm, 1.06\%, and 95.43\% respectively for Nd elements. Whereas for the Ce element the values are $31.69 \mathrm{ppm}, 108.78 \mathrm{ppm}, 1.43 \%$ and $95.77 \%$,
\end{abstract}

Keywords: method validation, La standard, neodymium and cerium solution, XRF 


\section{PENDAHULUAN}

Menurut Kim (1989), pada industri nuklir, Neodimium (Nd) merupakan salah satu isotop hasil fisi yang digunakan sebagai indikator burn-up bahan bakar pasca iradiasi, karena isotop $\mathrm{Nd}$ merupakan aktinida hasil fisi yang independen dan mempunyai tampang lintang penangkap neutron yang rendah. Sementara menurut Kim (2015) "Pada analisis isotopik dengan spektrometri massa, selain isotop $\mathrm{Nd}$ juga terdapat hasil fisi berupa isotop Serium (Ce)". Nd dan Ce bersifat isobar, sehingga $\mathrm{Nd}$ sebagai indikator burn-up perlu dipisahkan dari $\mathrm{Ce}$ agar tidak menganggu dalam perhitungan burn-up. Menurut Charalampides (2015), Nd dan $\mathrm{Ce}$ merupakan unsur-unsur golongan logam tanah jarang yang banyak terkandung dalam mineral tanah jarang seperti pasir monasit, bastnasit dan xenotim. Nd dalam industri mempunyai nilai ekonomis tinggi karena dimanfaatkan sebagai magnet, katalis, polimerisasi, kapasitor keramik elektrolik, gelas berwarna dan sebagainya.Ce juga banyak digunakan pada serbuk poles, keramik, fosfor, gelas kaca, katalis, pigmen, filter UV, dan lainlain.

Berdasarkan manfaat dan besarnya perannya dalam industri nuklir dan non nuklir, maka analisis unsur $\mathrm{Nd}$ dan Ce penting untuk dipelajari. Pada penelitian sebelumnya telah dilakukan analisis $\mathrm{Nd}$ menggunakan spektrofotometer UV-Vis. Dari kegiatan tersebut diketahui analisis menggunakan metode ini cukup baik pada konsentrasi $\mathrm{Nd}$ antara 1 hingga $7 \mathrm{ppm}$ dengan akurasi 96,73\%sampai 99,86\%. Spektrofotometer UVVis hanya dapat digunakan untuk analisis unsur tunggal dalam sampel karena bila terdapat unsur-unsur lain dalam sampel akan mengganggu dalam pengukuran karena unsur lain juga membentuk senyawa komplek yang sama dengan unsur yang dianalisis. Metode lain yang dapat digunakan untuk analisis unsur $\mathrm{Nd}$ dan Ce yaitu metode spektrometri XRF. Dengan metode ini, keberadaan unsur-unsur lain dalam suatu sampel uji tidak akan mempengaruhi hasil analisis karena setiap unsur memiliki energi sinar- $X$ karakteristik sehingga dapat dilakukan analisis multi unsur dalam sampel. Menurut Khalid (2016), "Spektrometer XRF merupakan alat uji tak merusak yang digunakan untuk analisis komposisi kimia secara kualitatif dan kuantitatif dalam bahan padat masif, serbuk maupun cair". Sementara menurut Daly (2017), analisis kualitatif dilakukan untuk menentukan jenis unsur yang terkandung dalam bahan sehingga komposisi kimia bahan dapat diketahui, sedangkan analisis kuantitatif dilakukan untuk menentukan konsentrasi unsur dalam bahan.

Analisis unsur dalam sampel cair menggunakan XRF dilakukan pengukuran secara langsung atau disiapkan menggunakan media sehingga berbentuk padat. Penyiapan sampel cair dalam bentuk padat berdasarkan pertimbangan keselamatan dan pengembangan metode. Preparasi sampel cair menggunakan media perlu dipastikan bahwa unsur yang akan dianalisis tidak terdapat dalam media yang digunakan. Menurut Okuda (2016), teknik tetes adalah salah satu teknik preparasi pada penentuan kandungan unsur dalam sampel cair dengan cara meneteskan pada media, biasanya digunakan kaca preparat atau kertas saring berbentuk lingkaran dengan diameter tertentu dan dikeringkan. Sedangkan menurut Macis (2018), "Berdasarkan serapan sampel cair dengan volume tertentu pada permukaaan media maka kandungan unsur dalam sampel dapat terdeteksi". Untuk menjamin hasil yang akurat maka analisis sampel cair dengan metode tetes menggunakan XRF perlu dilakukan validasi.

\section{TINJAUAN PUSTAKA}

Sebelum digunakan untuk analisis, maka untuk mengetahui unjuk kerja yang konsisten, maka suatu metode perlu dilakukan validasi berdasarkan ISO-17025-2017. Validasi metode merupakan suatu proses konfirmasi melalui pengujian dan pengadaan bukti yang obyektif. Dalam proses validasi metode, parameterparameter unjuk kerja metode ditentukan dengan menggunakan peralatan yang memenuhi spesifikasi, bekerja dengan baik dan terkalibrasi secara memadai. Secara umum, validasi metode mencakup penentuan yang berkaitan dengan alat dan metode. Pada kegiatan ini validasi metode dibatasi pada penentuan yang berkaitan denganparameter konfirmasi identitas, limit deteksi dan limit kuantitasi, akurasi yang dihitung dengan cara membandingkan antara konsentrasi yang diperoleh dari pengukuran dengan nilai konsentrasi yang diketahui, dan presisi yang dilakukan dengan uji ripitabilitas dari standar.

Konfirmasi identitas pada analisis unsur menggunakan spektrometer XRF dilakukan untuk mengetahui bahwa respon yang dihasilkan pada pengukuran hanya berasal dari analit bukan berasal dari senyawa lain atau bukan merupakan campuran respon dari analit dengan senyawa lain yang mempunyai sifat fisika/kimia serupa dengan analit yang ditetapkan. 
Menurut Erlina (2012), linieritas adalah kemampuan metode untuk memberikan hasil uji/pengukuran yang proporsional terhadap penunjukan standar sekunder/bahan acuan dari sampel pada rentang tertentu. Linieritas metode dapat diamati dengan melakukan plot (secara grafis) hasil uji/pengukuran $Y$ terhadap nilai pengukuran standar/bahan acuan. Linieritas kurva dinyatakan dalam istilah variansi sekitar arah garis regresi yang dihitung berdasarkan persamaan matematik data yang diperoleh dari hasil analisis unsur dalam larutan standar dengan konsentrasi yang bervariasi (deret standar). Untuk menentukan linieritas, maka variasi konsentrasi yang digunakan sekurang-kurangnya sebanyak lima standar. Persamaan yang dihasilkan dari linieritas adalah

$$
\mathrm{Y}=\mathrm{aX}+\mathrm{b}
$$

$\mathrm{a}=$ varian $\mathrm{y}$ memberikan ukuran matematis linieritas(sensitifitas)/slope

$\mathrm{b}=$ ukuran bias potensial dari metode (zero offset)/penyimpangan/intercept

Sementara itu menurut Harmita (2004), "Hubungan linier yang ideal dicapai jika nilai $b$ $=0$ dan $\mathrm{r}=+1$ atau -1 bergantung pada arah garis, sedangkan nilai a menunjukkan kepekaan analisis terutama instrumen yang digunakan".

Menurut Ravichandran (2010), "rentang atau range adalah batas ukur bawah dan batas ukur atas yang dapat memberikan hasil uji dengan presisi, akurasi dan linearitas yang dipersyaratkan untuk kondisi pengujian tertentu". Sedangkan menurut ravisangkar (2015), "limit deteksi (LoD) adalah konsentrasi terendah dari analit dalam contoh yang dapat terdeteksi, tetapi tidak perlu terkuantitasi dibawah kondisi pengujian yang disepakati”.

$\mathrm{LoD}=$ rata-rata blanko $+3 \mathrm{SD}$

LoD = Limit atau batas deteksi (ppm)

$\mathrm{SD}=$ Standar deviasi blanko

Limit kuantitasi/Limit of Quantitation (LoQ) atau biasa disebut juga limit pelaporan (Limit of Reporting) adalah konsentrasi terendah dari analit yang dapat ditentukan dengan tingkat presisi dan akurasi yang dapat diterima, di bawah kondisi pengujian yang disepakati.

$L o Q=$ rata-rata blanko $+10 S D$

LoQ = Limit atau batas kuantitasi (ppm)

SD = Standar deviasi blanko

Secara umum, penentuan limit deteksi
danlimit kuantitasi dilakukan dengan menganalisis blanko, selanjutnya dikonversi ke persamaan kurvakalibrasi yang merupakan hubungan antara konsentrasi dan cacahan. Hasil analisis blanko sebanyak 10 data dihitung konsentrasi rerata $(\mathrm{X}$ rt) dan standar deviasinya (SD).

Presisi digambarkan dengan harga ripitabilitas pengukuran. Ripitabilitas ditentukan dari nilai standar deviasi yang diperoleh dari $3 x$ pengulangan pengukuran sampel. Perhitungan presisi menggunakan persamaan Coefficient of Variation (CV) dengan persamaan :

$$
C V(\%)=\frac{S D}{\text { xrerata }} \times 100 \%
$$

$\mathrm{SD} \quad=$ standar deviasi

$\mathrm{X}$ rerata $=$ rata-rata konsentrasi sampel $(\mathrm{ppm})$

Untuk keberterimaannya dilakukan pengujian dengan persamaan Horwitz menggunakan rumus:

CV Horwitz $(\%)=2^{1-0.5 \log \text { rerata pengukuran }}$

Hasil suatu pengujian dapat diterima jika coefficient of variation (CV) pengukuran lebih kecil dari CV Horwitz.

Akurasi merupakan kedekatan hasil uji dengan nilai konsentrasi sebenarnya. Presisi adalah ukuran yang menunjukkan derajat kesesuaian antara hasil uji individual, diukur melalui penyebaran hasil individual dari rerata jika prosedur diterapkan secara berulang pada sampel yang diambil dari campuran yang homogen.Presisi pengukuran suatu metode diperoleh dengan cara melakukan uji repeatability yang dilakukan berulang kali oleh analis yang sama, pada kondisi yang sama, dan dalam interval waktu yang pendek.

Nilai akurasi dihitung berdasarkan selisih nilai pengukuran dan nilai sebenarnya dengan persamaan:

Bias/Deviasi $(\%)=$

$\frac{\text { selisih pengukuran \& nilai benar }}{\text { nilai benar }} \times 100 \%$

Akurasi $(\%)=100 \%-\%$ Bias

\section{METODE PENELITIAN}

\section{Bahan dan Alat}

Bahan-bahan yang digunakan pada penelitian ini antara lain: larutan standar unsur Cerium (Ce), Neodimium (Nd), Lanthanum (La)SPEX 10000 ppm, dan air bebas mineral (ABM).

Alat yang digunakan adalah spektrometer X-Ray Fluorescence (XRF), 
lampu infra merah, kertas saring Whatman No. 41yang digunting berbentuk lingkaran (diameter $27 \mathrm{~mm}$ ), mylar,sample holder dan beberapa peralatan gelas untuk penyiapan larutan.

\section{Cara Kerja}

Larutan standar dibuat konsentrasi yang bervariasi yaitu $0,200,400,600,800$ dan 1000 ppm dengan cara mengencerkan larutan standar induk (unsur $\mathrm{Nd}$ dan $\mathrm{Ce}$ ) dengan $\mathrm{ABM}$, kemudian ditambahkan sejumlah standar $\mathrm{La}$ sebagai standar pembanding. Masing-masing larutan diteteskan pada media kertas saring yang diletakkan di atas sample holder sebanyak $10 \mu \mathrm{L}$ sambil dikeringkan di bawah lampu infra merah. Jika sudah kering diulangi hingga 5 kali sehingga volume yang diteskan menjadi $50 \mu \mathrm{L}$. Kertas saring ditutup mylar kemudian dicacah menggunakan spektrometer XRF.

Pada pelaksanaan validasi metode unsur $\mathrm{Nd}$ dan $\mathrm{Ce}$, konfirmasi identitas dilakukan dengan pencacahan terhadap masing-masing larutan standar $\mathrm{Nd}$ dan $\mathrm{Ce}$. Linieritas ditentukan dengan cara melakukan pencacahan setiap unsur pada beberapa tingkatan konsentrasi.Limit deteksi dan limit kuantitasi ditentukan dengancara melakukan pencacahan setiap unsur terhadaplarutan blanko sebanyak 10 kali pengulangan.Uji akurasi dan presisi dilakukan dengan melakukan pengukuran pada salah satu konsentrasi standar sebanyak 7 kali pengulangan.

\section{HASIL DAN PEMBAHASAN}

Konfirmasi identitas pada analisis unsur $\mathrm{Nd}$ dan Ce menggunakan spektrometer XRF dilakukan untuk memastikan energi puncak analit tidak berhimpit dengan energi puncak standar La. Unsur La digunakan sebagai standar pembanding karena mempunyai energi yang berimpit dengan $\mathrm{Nd}$. Hasil konfirmasi identitas unsur $\mathrm{Nd}$ dan $\mathrm{Ce}$ menggunakan spektrometer XRF ditunjukkan pada Gambar 1 untuk unsur $\mathrm{Nd}$ danspektrumunsur $\mathrm{Ce}$ ditunjukkan pada Gambar 2.

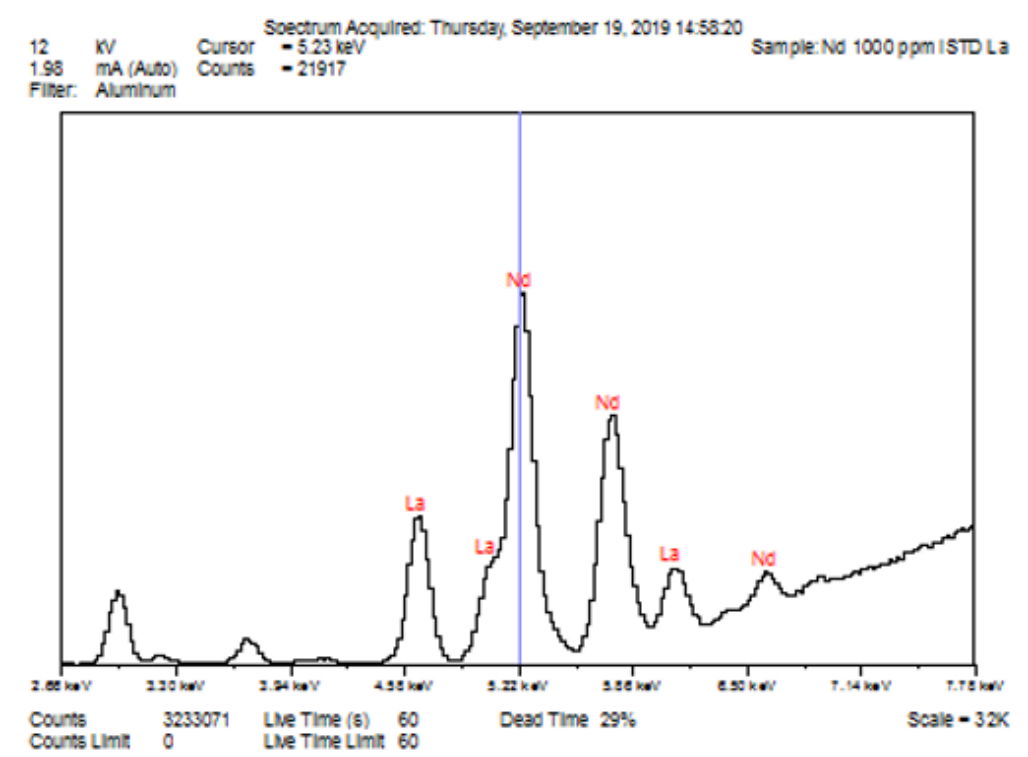

Gambar 1. Spektrum XRF standar Nd dengan La sebagai standar pembanding 


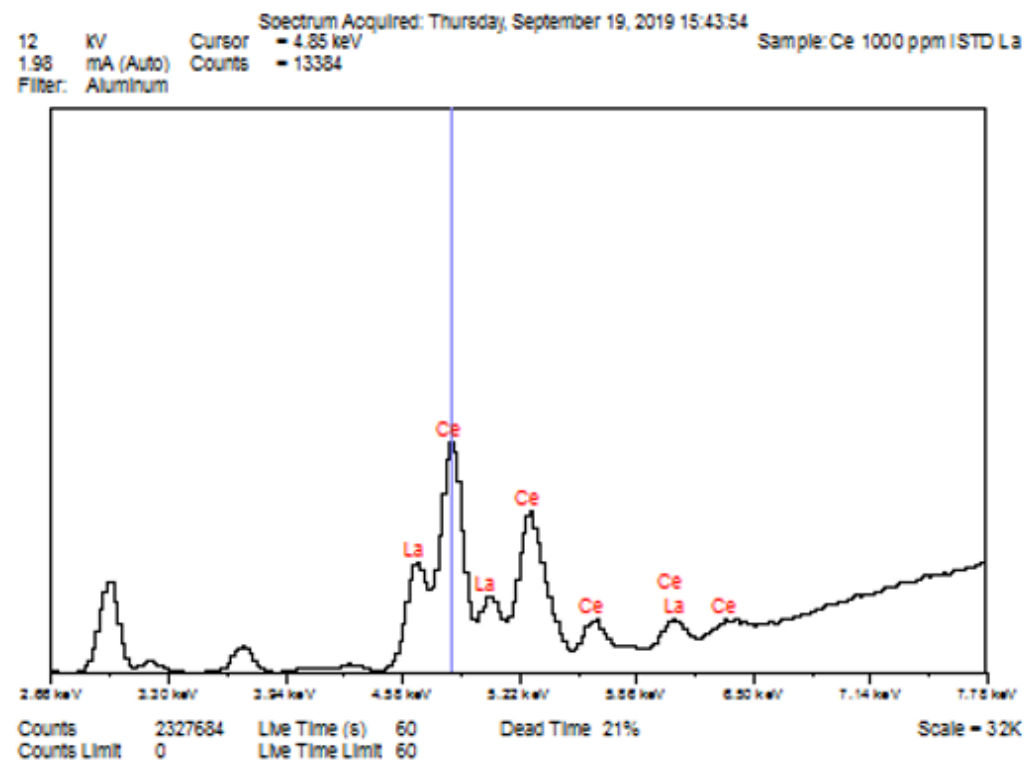

Gambar 2. Spektrum XRF standar Ce dengan La sebagai standar pembanding

Sesuai dengan Gambar 1 dan Gambar 2 maka unsur $\mathrm{Nd}$ membentuk spektrum pada energi sinar-X 5,23 keV (L $\alpha)$ dan 5,75 keV (Lß). Spektrum unsur Ce pada energi sinar- $X$ 4,85 $\mathrm{keV}(\mathrm{L} \alpha)$ dan $5,27 \quad \mathrm{keV}(\mathrm{L} \beta)$ sedangkan spektrum unsur La pada energi 4,65 $\mathrm{keV}(\mathrm{L} \alpha)$ dan 5,05 keV (L $\beta$ ). Menurut Noviarty (2020), "La digunakan sebagai pembanding karena $\mathrm{Nd}$ dan $\mathrm{Ce}$ termasuk deret unsur lantanida sehingga mempunyai sifat kimia yang mirip tetapi tidak mengganggu energi yang dianalisis". Salah satu puncak energi dari Nd, $\mathrm{Ce}$ dan $\mathrm{La}$ ada yang saling berimpit, yaitu $\mathrm{Nd}$ $(L \alpha)$ berimpit dengan $\mathrm{Ce}(\mathrm{L} \beta)$ sehingga tidak bisa digunakan untuk evaluasi kurva kalibrasi. Oleh karena itu, untuk evaluasi kurva kalibrasi digunakan energi pendampingnya yang tidak saling berimpit yaitu $\mathrm{Nd}(\mathrm{L} \beta)$ dan $\mathrm{Ce}(\mathrm{L} \alpha)$.

Hasil analisis regresi menggunakan model $Y=a X+b$ dapat dilihat pada Tabel 1 dengan kurva kalibrasi Nd pada Gambar 3, dan kurva kalibrasi Ce pada Gambar 4.

Tabel 1 Hasil analisis regresi

\begin{tabular}{|c|c|c|c|c|c|c|}
\hline \multirow[t]{2}{*}{ NO. } & \multicolumn{4}{|c|}{ UNSUR Nd } & \multicolumn{2}{|c|}{ UNSUR Ce } \\
\hline & $\begin{array}{c}\text { KONSENTRASI } \\
\text { Nd/Ce } \\
\text { (PPM) }\end{array}$ & $\begin{array}{c}\text { CACAH La } \\
\text { RERATA }\end{array}$ & $\begin{array}{l}\text { CACAH Nd } \\
\text { RERATA }\end{array}$ & RASIO Nd/La & $\begin{array}{c}\text { CACAH Ce } \\
\text { RERATA }\end{array}$ & RASIO Ce/La \\
\hline 1 & 0 & 6550 & 1067 & 0,1628 & 201 & 0,0306 \\
\hline 2 & 200 & 8707 & 4389 & 0,5041 & 3965 & 0,4554 \\
\hline 3 & 400 & 8212 & 7016 & 0,8544 & 7090 & 0,8634 \\
\hline 4 & 600 & 9230 & 10576 & 11,459 & 11575 & 12,542 \\
\hline 5 & 800 & 9656 & 14074 & 14,582 & 15676 & 16,244 \\
\hline \multirow[t]{2}{*}{6} & 1000 & 8147 & 14367 & 17,636 & 16268 & 19,969 \\
\hline & & & TANPA La & DENGAN La & TANPA La & DENGAN La \\
\hline 7 & Slope, b & & 1501,5 & 0,1840 & 560,95 & 0,056 \\
\hline 8 & Intercept, a & & 14,16 & 0,0016 & 17,136 & 0,0020 \\
\hline 9 & Koefisien korelas & & 0,9738 & 0,9990 & 0,9772 & 0,9992 \\
\hline
\end{tabular}




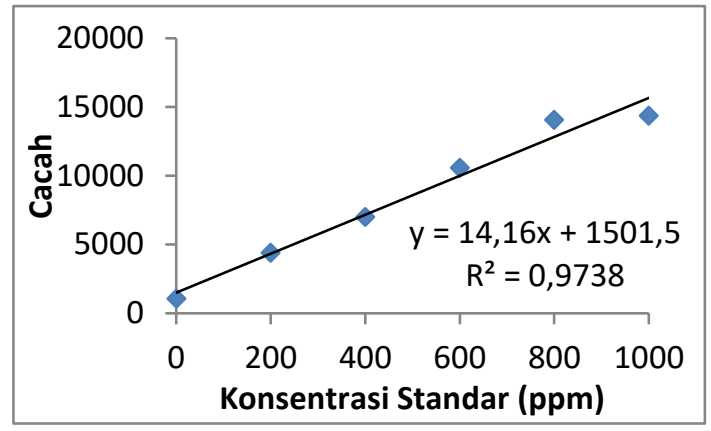

(a)

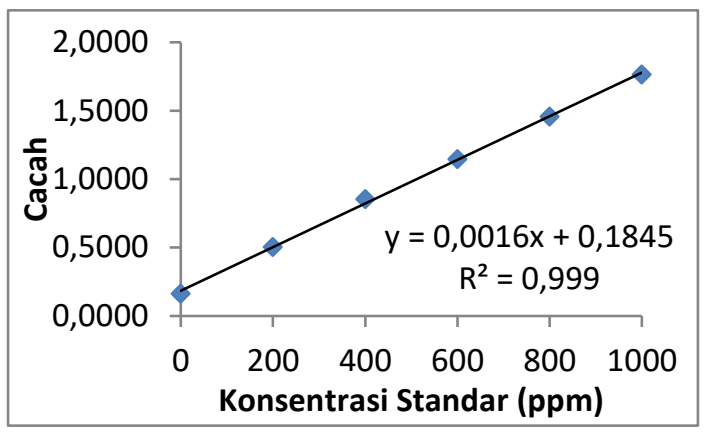

(b)

Gambar 3. Kurva kalibrasi Nd : (a) tanpa La, (b) dengan La

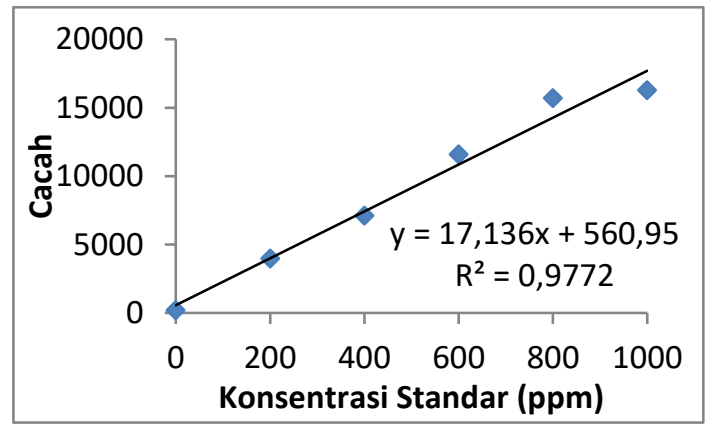

(a)

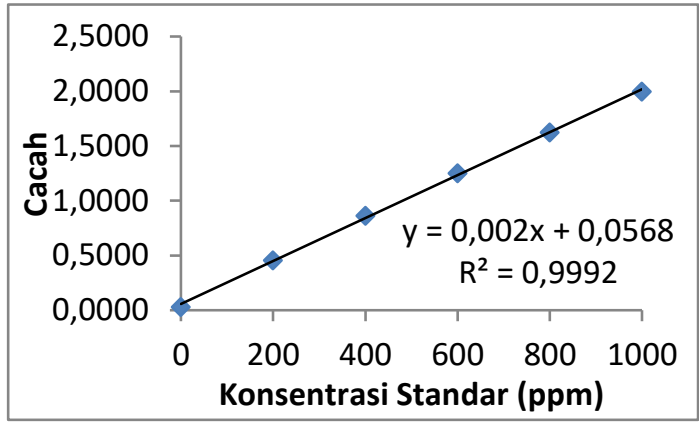

(b)

Gambar 4. Kurva kalibrasi Ce : (a) tanpa La, (b) dengan La

Berdasarkan nilai koefisien korelasi yang diperoleh, dapat dilihat bahwa penggunaan standar La memberikan nilai koefisien regresi yang lebih baik, yaitu lebih mendekati nilai 1, baik kurva kalibrasi $\mathrm{Nd}$ maupun $\mathrm{Ce}$.Hal ini disebabkan dengan menggunakan perbandingan maka faktor kestabilan kurva menjadi terkoreksi [8]. Rentang metode merupakan pernyataan batas terendah dan tertinggi analit yang sudahditunjukkan dapat ditetapkan dengan kecermatan, keseksamaan dan linieritas yang dapat diterima.Rentang metode unsur $\mathrm{Nd}$ dan $\mathrm{Ce}$ berada pada batasterendah 200 ppm dan batas tertinggi 1000 ppm. Dengan adanya rentang metode ini, pengukuran sampel dilakukan pada daerah kerja tersebut. Apabila konsentrasi sampel terlalu tinggi, perlu dilakukan pengenceran sehingga konsentrasinya masuk ke dalam rentang metode tersebut.

Hasil perhitungan limit deteksi (LoD) dan limit kuantitasi (LoQ) unsur $\mathrm{Nd}$ dan $\mathrm{Ce}$ ditunjukkan pada Tabel 2.
Tabel 2 LoD dan LoQ

\begin{tabular}{|c|c|c|c|}
\hline NO & UNSUR & $\begin{array}{c}\text { LoD } \\
\text { (PPM) }\end{array}$ & $\begin{array}{c}\text { LoQ } \\
\text { (PPM) }\end{array}$ \\
\hline 1 & $\mathrm{Nd}$ & 31,69 & 108,78 \\
\hline 2 & $\mathrm{Ce}$ & $-8,94$ & 0,76 \\
\hline
\end{tabular}

Berdasarkan persamaan [4] dan [7] diperoleh nilai presisi dan akurasi yang ditampilkan pada Tabel 3. Nilai presisi $\mathrm{Nd}$ dan Ce tanpa La lebih besar dari CV Horwitz, sedangkan nilai presisi $\mathrm{Nd}$ dan $\mathrm{La}$ menggunakan standar La lebih kecil dari CV Horwitz. Hal ini menujukkan bahwa penggunakan standar pembanding La sangat mempengaruhi presisi pengukuran. Perhitungan presisi berdasarkan persamaan Berdasarkan Tabel 3 menunjukkan bahwa nilai presisi dan akurasi yang diperoleh pada analisis dengan menggunakan standar La, baik untuk Nd maupun Ce telah memenuhi kriteria keberterimaan secara statistik yaitu lebih besar dari $95 \%$. 
Tabel 3 Data presisi, CV Horwitz dan akurasi Nd dan Ce

\begin{tabular}{|c|c|c|c|c|c|}
\hline \multirow[t]{2}{*}{ No } & \multirow{2}{*}{ PENGULANGAN } & \multicolumn{2}{|c|}{$\begin{array}{l}\text { KONSENTRASI Nd } \\
\text { (PPM) }\end{array}$} & \multicolumn{2}{|c|}{$\begin{array}{c}\text { KONSENTRASI Ce } \\
\text { (PPM) }\end{array}$} \\
\hline & & TANPA La & DENGAN La & TANPA La & $\begin{array}{c}\text { DENGAN } \\
\text { La }\end{array}$ \\
\hline 1 & 1 & 415,84 & 529,96 & 402,79 & 528,89 \\
\hline 2 & 2 & 444,55 & 527,35 & 433,47 & 523,56 \\
\hline 3 & 3 & 572,31 & 520,31 & 575,46 & 513,30 \\
\hline 4 & 4 & 471,57 & 527,35 & 457,74 & 516,66 \\
\hline 5 & 5 & 418,74 & 523,30 & 410,98 & 527,39 \\
\hline 6 & 6 & 377,52 & 512,93 & 373,23 & 527,92 \\
\hline 7 & 7 & 500,44 & 518,79 & 493,42 & 510,42 \\
\hline 8 & Rata-rata & 457,28 & 522,86 & 449,58 & 521,16 \\
\hline 9 & Presisi (\%) & 14,83 & 1,06 & 15,74 & 1,43 \\
\hline 10 & CV Horwitz (\%) & 6,36 & 6,24 & 6,38 & 6,24 \\
\hline 11 & Akurasi (\%) & 91,46 & 95,43 & 89,92 & 95,77 \\
\hline
\end{tabular}

Penggunaan standar La dalam pengukuran $\mathrm{Nd}$ dan $\mathrm{Ce}$ mampu mengurangi faktor kesalahan analisis yaitu kehilangan pada proses preparasi, antara lain perbedaan volume larutan yang diteteskan ke kertas saring, area tetesan larutan di atas kertas saring, maupun area pencacahan pada spektrometer XRF. Hal-hal tersebut tidak akan berpengaruh terhadap hasil analisis karena rasio analit terhadap standar La akan selalu sama (tetap) pada setiap proses preparasi.

\section{KESIMPULAN}

Metode tetes dapat digunakan untuk analisis $\mathrm{Nd}$ dan $\mathrm{Ce}$ dari sampel berbentuk cairan menggunakan spektrometer XRF. Metode analisis unsur $\mathrm{Nd}$ dan $\mathrm{Ce}$ pada sampel berbentuk cairan menggunakan metode tetes telah tervalidasi, Pengukuran $\mathrm{Nd}$ dan $\mathrm{Ce}$ dengan metode tetes dengan menambahkan standar La memberikan hasil yang akurat dengan tingkat kepercayaan secara statistik > $95 \%$.

\section{UCAPAN TERIMA KASIH}

Terima kasih kepada Ir. Sungkono M.T, sebagai koordinator Uji Radometalurgi dan Ir. Aslina Br. Ginting sebagai peneliti utama yang telah menyetujui dan memberikan masukan $\mathrm{KTI}$ ini untuk diajukan ke webinar PPIS 2020.

\section{DAFTAR PUSTAKA}

Kim, J.S., S. H. Han, M. Y. Suh, K. S. Joe, and T. Y. Eom (1989), Burnup Measurement of Irradiated Uranium Dioxide Fuel by Chemical Methods,J. Korean Nucl. Soc., vol. 21, no. 4, pp. 277-286.

Kim, J.S., Y. S. Jeon, S. D. Park, Y. K. Ha, and K. Song (2015), Analysis of high burnup pressurized water reactor fuel using uranium, plutonium, neodymium, and cesium isotope correlations with burnup, Nucl. Eng. Technol., vol. 47, no. 7, pp. 924-933.

Charalampides, G., K. I. Vatalis, B. Apostoplos, and B. Ploutarch-Nikolas (2015), Rare Earth Elements: Industrial Applications and Economic Dependency of Europe,Procedia Econ. Financ., vol. 24, no. 15 , pp. 126-135.

Khalid, R.S., M. Alaama, and S. A. Abbas (2016), Main Analytical Techniques Used for Elemental Analysis in, vol. 15, no. February, pp. 427-434

Daly, K., and A. Fenelon (2017), A rapid and multi-element method for the analysis of major nutrients in grass ( Lolium perenne ) using energy-dispersive $X$-ray fluorescence spectroscopy, Irish Journal of Agricultural and Food Research, pp. $1-11$.

Okuda, K. (2016), Liquid analysis by total reflection $X$-ray fluorescence 
spectrometer, Rigaku Journal, vol. 32, no. 2, pp. 17-18.

Macis, S. et al.(2018), Microdrop Deposition Technique: Preparation and Characterization of Diluted Suspended Particulate Samples, MDPI Journal, pp. 1-9.

Noerpitasari, E., and A. Nugroho (2012), Validasi Metode Analisis Unsur Tanah Jarang (Ce, Eu, Tb) Dengan Alat ICPAES Plasma 40,Semin. Nas. VIII SDM Teknol. Nukl., pp. 347-352.

Harmita (2004), Petunjuk Pelaksanaan Validasi, Departemen Farmasi FMIPA-UI, vol. I, no. 3, pp. 117-135

Ravichandran,V., S. Shalini, K. M. Sundram, and H. Rajak (2010), Validation of analytical methods - Strategies \& importance, Int. J. Pharm. Pharm. Sci., vol. 2, no. SUPPL. 3, pp. 18-22.

P. Ravisankar, C. Naga Navya, D. Pravallika, and D. N. Sri (2015), A review on stepby-step analytical method validation,IOSR J. Pharm., vol. 5, no. 10, pp. 2250-3013.

Noviarty, Erlina Noerpitasari, Rosika Kriswarini, Agus Jamaludin, Sutri Indaryati, Sayyidatun Nisa, Samsul Fatimah (2020), Penentuan Recovery Neodymium dan Cerium Pada Proses Pemisahan Isotop dari Simulasi PEB U3Si2/Al Pra Iradiasi, Urania, Jurnal IImiah Daur Bahan Bakar Nuklir, vol. 26, no. 1 , pp. $37-48$ 